\title{
Mapping Ravel's “La vallée des cloches”
}

\author{
Kyle Fyr
}

NOTE: The examples for the (text-only) PDF version of this item are available online at: https://www.mtosmt.org/issues/mto.20.26.4/mto.20.26.4.fyr.php

KEYWORDS: Ravel, map, bells, auditory landscape, analysis and performance

ABSTRACT: This article makes a case for constructing a map of Maurice Ravel's “La vallée des cloches" (The valley of the bells) by showing how the process of mapping the piece can provide valuable insights from a variety of perspectives, such as: 1) offering insights into how the piece's many bell sounds are individuated from each other and interact with one another in creating intricate formal and temporal frameworks; 2) emphasizing prominent aspects of Ravel's aesthetics such as mechanistic impulses, spatial and metaphorical thinking, literary influences, and nostalgic fascination with the past; 3) situating the piece within the context of significant changes in France at the turn of the twentieth century marked by the declining prominence of bells in defining the auditory landscape, the symbolism bells carried with them, and the role bells played in marking temporal rhythms for French society; and 4) showing how many aspects of the piece highlighted throughout the mapping process align in suggestive ways with significant performance considerations.

DOI: $10.30535 / \mathrm{mto} .26 .4 .3$

Received December 2019

Volume 26, Number 4, November 2020

Copyright $(92020$ Society for Music Theory

[1] Maurice Ravel once remarked that the harmonic evolution in his Miroirs "disconcerted musicians who until then had been thoroughly accustomed to [his] style" (Orenstein 2003, 30), a quote that could be equally applied to other aspects of the music as well. Epitomizing the confounding nature of Miroirs is the piece that closes the suite: "La vallée des cloches" (The valley of the bells). While ostensibly featuring little of the technical virtuosity for which Ravel's piano works are renowned, "La vallée des cloches" nevertheless presents a number of unique challenges for both performance and analysis. The piece's many layers of bell sounds produce a highly intricate contrapuntal texture, yet most of the individual strands that create that fabric are strikingly non-developmental. The form of the piece is also quite clearly defined by the recurrence of recognizable musical ideas, yet almost none of those musical ideas can be considered thematic or melodic in any traditional sense. With such perplexing contradictions at its heart, the piece has perhaps unsurprisingly lent itself to widely varying interpretations by scholars and performers alike. $^{(1)}$

[2] I contend that a fruitful new approach to conceptualizing "La vallée des cloches" - one suited to the piece's unique nature-is to construct a spatial representation of the piece, or more succinctly, a 
map. In addition to offering valuable analytical insights, the process of constructing and grappling with such a map highlights important aspects of Ravel's aesthetics, suggests an illuminating historical and cultural context for the piece, and aligns in thought-provoking ways with significant performance considerations.

\section{Some initial aesthetic considerations}

[3] The case for conceiving of "La vallée des cloches" in spatial terms can be made on a number of aesthetic grounds, some of which Ravel alluded to in a June 1905 letter to Maurice Delage, the eventual dedicatee of the piece. In this letter, written while on holiday with friends in the Netherlands, Ravel vividly describes an outing that profoundly influenced him.

Yesterday, an excursion to Alkmaar: a cheese market with carillons ringing ceaselessly. En route, a most magnificent sight: a lake bordered by windmills, and in the fields, windmills as far as the horizon. No matter where you looked, you saw nothing but revolving vanes. Viewing this mechanical landscape, you could end up believing yourself to be an automaton. With all that, I don't need to tell you that I'm not doing a thing. But I am storing things up, and I believe that a lot will come out of this trip. (Orenstein 2003, 69-70)

A lot came out of this trip indeed. Six months later Ravel had completed Miroirs, and in "La vallée des cloches" one can find music suffused with ceaselessly ringing bells whose sounds vividly evoke the notion of such a "mechanical landscape."

[4] Considering "La vallée des cloches" in the context of the quote above strongly suggests the idea of music that represents something physical or spatial in nature, exemplifying a tendency in Ravel's music to engage with events of the outside world by attempting to translate these events directly into sound (Nichols 2011, 19). This proclivity prompted Vladimir Jankélévitch to refer to Ravel as a "master of objects" who "manufactured" musical objects that imitate life $(1959,76)$. One of the most prominent ways that Ravel imitates actual bell sounds in this piece is through frequent repetition of the individual bell motives, an approach typifying a predilection toward the mechanical that a number of scholars have observed in his music. ${ }^{(2)}$ An important aspect of repetition is that, as Elizabeth Margulis notes, it "tends to reify a passage-to set it apart from the surrounding context as a 'thing' to be mused on, abstractly considered, and conceptualized as a unit" $(2013,43)$. By using repetition, Ravel therefore imbues the bell sounds in this piece with mechanistic qualities, which by extension facilitate their depiction as objects in a physical or spatial environment.

[5] Of course, the bells depicted in this piece are not literally physical objects, so conceiving of the music in spatial or physical terms requires us to think metaphorically. Such a metaphorical conception would not have been foreign to Ravel, however, as indicated by the Shakespeare quote that he referenced to describe his aesthetic reasons for titling the suite Miroirs: "The eye sees not itself. But by reflection, by some other things" (Orenstein 2003, 35). Ravel's widely acknowledged fascination with the writings of Charles Baudelaire provides further evidence of such metaphorical thinking. ${ }^{(3)}$ Ravel would certainly have known of Baudelaire's celebrated 1857 poem "Correspondances," the main idea behind which is a holistic view that the material world suggests more abstract meanings, marking what Barbara Wright calls "a powerful union of the physical and the non-physical" $(2005,33)$. "La vallée des cloches" thus occupies an interesting position between realism and metaphor. As Alexandra Kieffer asserts, "what is so compelling about this piece is precisely that it presents its listeners with such remarkable and striking moments of apparent realism, only to fold back that realism into further layers of an idealized musicality" $(2017,458)$.

[6] Why might Ravel have chosen bells as the objects to be represented in this musical landscape? Nichols $(2011,11)$ suggests a longtime attraction in this regard: that after hearing Javanese gamelan music at the Fourth Paris International Exhibition in 1889, Ravel's music over the ensuing years was "shot through with the resonance of bells, explicit or implicit." The word resonance is important here, as Ravel felt most intuitively connected to music that was "bathed in sonorous 
fluid" (Orenstein 1991, 126). ${ }^{(4)}$ There are also numerous precedents among earlier French composers for incorporating bell sounds into keyboard music: for example, Ravel's teacher Gabriel Fauré noted subtle references to bell sounds in the opening of his Nocturne, op. 33, no. 2 (see Nectoux 1991, 92), and Fauré's teacher Camille Saint-Saëns composed a number of explicitly bellinfluenced works such as Les cloches $d u$ soir, op. 85 (see Kieffer 2017, 447-48). ${ }^{(5)}$ Literary influences may have been another contributing factor: the imagery of bells was a significant theme in Baudelaire's poetry as well as that of Edgar Allan Poe, whose influence on Ravel has also been widely cited. (6) Finally, Ravel's evocation of bells in this piece also suggests a symbolic connection to some significant historical and cultural developments in France at the beginning of the twentieth century.

\section{The "auditory landscape" in turn-of-the-century France}

[7] By telling the pianist Robert Casadesus that "La vallée des cloches" was inspired by the sound of bells at noontime in Paris (Marnat 1986, 184), Ravel strongly implied that the music was meant to evoke a spatiotemporal metaphor representing a specific time and place. The act of composing such a piece in France in 1905 is not without a certain symbolism as well. The following exploration of some prominent historical and cultural developments involving bells during the nineteenth and early twentieth centuries in France will shed light on the symbolic significance of Ravel's decision to musically depict a landscape of bells at this particular time in France's history.

[8] The French historian Alain Corbin's groundbreaking book Village Bells provides a unique window into French history by examining an "auditory landscape" in which bells not only served many practical purposes but also carried with them deeply symbolic meanings. The physical properties of bell sounds were fundamental in the creation of such a landscape, as they served to define an auditory space with readily perceptible limits: an enclosed space circumscribed by the sounds of the bell tower that radiated outward from its center (Corbin 1998, 95-97). ${ }^{\text {(7) }}$ The omnipresent sounds of bells within nineteenth-century French communities also significantly impacted the social consciousness of those communities. Many French authors of the time, including François-René de Chateaubriand and Victor Hugo, emphasized the power of bell sounds as an expression of rootedness and memory; Corbin notes that "Like the scent of a flower it was a matter of instant recall" (290-92). As such, the absence of these bell sounds could be equally jarring to the psyche. For example, in "La cloche fêlée" ("The cracked bell") from Les fleurs du mal, Baudelaire deplores the fact that the cracked bell represents a fracture in his soul, which is now unable to access the distant memories evoked by the bell sounds (306). ${ }^{(8)}$ Why might the sounds of bells have been so imprinted upon French people's memories and why was the thought of their absence treated with such a sense of foreboding? The answer to this question lies in the fact that in France at the turn of the twentieth century, the auditory landscape Corbin describes had begun to disintegrate.

[9] In France, the ringing of bells, which had long served as auditory signals marking temporal rhythms for communities and for individuals within those communities, was subject to local control and sudden changes to these routines were met with strong resistance (Corbin 1998, 11014). Locally controlled timekeeping was in fact typical in much of the world for most of the nineteenth century - Stephen Kern $(2003,12)$ notes that "Around 1870, if a traveler from Washington to San Francisco set his watch in every town he passed through, he would set it over two hundred times." Sweeping changes were on the horizon, however. In 1884, representatives from twenty-five countries convened at the Prime Meridian Conference in Washington, D.C. At this conference, Greenwich was proposed as the zero-degree meridian, the world was divided into twenty-four time zones, and a fixed, precise method of timekeeping was formulated. Yet, France was slow to adopt such timekeeping standards and "at the dawn of the twentieth century France remained a patchwork of customs and systems of temporal markers" (Corbin 1998, 114). Some regions of France during this era had as many as four different times within them, none of which aligned with Greenwich Time. Even when France adopted Paris Time-which was itself nine minutes and twenty-one seconds ahead of Greenwich Time-as a national law in 1891, railroads in Paris actually ran five minutes behind the official time. In a sense, it was (at least initially) a source 
of local and national pride for France to resist adopting the Greenwich standards (Kern 2003, 13).

By 1912, however, France had taken the lead in establishing the system of standardized world time, with Paris now at the center of the system's implementation.

The observatory at Paris would take astronomical readings and send them to the Eiffel Tower, which would relay them to eight stations spaced over the globe. At 10 o'clock on the morning of July 1, 1913, the Eiffel Tower sent the first time signal transmitted around the world. The independence of local times began to collapse once the framework of a global electronic network was established. Whatever charm local time might have once had, the world was fated to wake up with buzzers and bells triggered by impulses that traveled around the world with the speed of light. (Kern 2003, 14)

[10] These events show that French society, and specifically its attitude toward timekeeping, changed dramatically in a relatively short period from roughly 1880 to 1915 . Perhaps not coincidentally, by the beginning of the twentieth century the use of bells in France had begun to decline, and thus the deeply felt meanings with which they were associated began to fade as well. Ironically, the dissolution of the bell-saturated nineteenth-century French auditory landscape did not correspond with a decline in the size of bells or the volume of their sounds; in fact, the reverse was true:

Village bells were both louder and of superior quality in 1880 than they had been at the beginning of the July Monarchy [in 1830]. It was rather that their meaning seemed to fall away, modes of attention collapsed, the usages and rhetoric of bells grew narrower so that, in short, a whole range of auditory messages were increasingly disqualified. (Corbin 1998, 307)

Indeed, the world's largest swinging bell, "La Savoyarde" - which Ravel told the pianist Henriette Faure was represented in the final chords of "La vallée des cloches" (Faure 1978, 77) - was installed at the Sacré-Cœur basilica in Paris in 1895, just as the uses of and meanings of bells in France had begun to enter a state of seemingly irreversible decline. Though France would eventually adopt standardized time, the longstanding significance of bells in the national consciousness helps explain the strength of its initial resistance to the idea.

[11] Nostalgia for bells and the meanings they represented thus figured prominently in the French collective psyche. In an interesting parallel, Ravel's student and biographer Alexis Roland-Manuel specifically used the word "nostalgic" to describe "La vallée des cloches" $(1914,16)$, and in recent Ravel scholarship the notion of nostalgia has also been frequently invoked as a means of describing Ravel's fascination with the past. ${ }^{(9)}$ Viewed in this light, Ravel's depiction of an auditory landscape through musical sound in "La vallée des cloches" may be informed by suggestions of nostalgia stemming from the disintegration of this auditory landscape and the potent symbolism surrounding it. Paradoxically, the manner in which Ravel musically depicts this landscape is almost arrestingly novel, as the sounds of the various bells intertwine with each other in elegantly complex counterpoint yet most of the bell sounds are individually repetitive and strikingly nondevelopmental. "La vallée des cloches" thus presents a fascinating contradiction, or perhaps even coexistence, between memory and innovation: the piece's bell-saturated auditory landscape conjures up the nostalgic associations of bells in the French collective consciousness, but in order to depict this landscape in such a vividly spatialized way, Ravel had to employ a strikingly novel musical approach.

\section{Preliminary mapping considerations}

[12] Having situated "La vallée des cloches" among important aspects of Ravel's aesthetics as well as prominent historical and cultural developments in France at the turn of the twentieth century, I now turn my attention to the process of constructing a map of this "valley." A few significant considerations need to be addressed prior to the creation of such a map. Bells seem to be the obvious musical objects of choice and, as such, a logical first step in constructing a map of this valley is to determine just how many different bell sounds there are. Doing so presents some 
interesting challenges, some of which are evident right from the opening measures, as illustrated in Example 1. In mm. 1-2, there appear to be two distinct bell sounds, one played in each hand. When the chime-like stream of sextuplets enters in $\mathrm{m}$. 3, the issue becomes clarified, however, as the staggered octaves from the first two measures are now grouped together on a single staff and, practically speaking, are now played by a single hand (the left). It turns out that the upper octaves always follow the lower octaves (at a semi-regular time interval), and the tolling parallel fourths that first enter in m. 4 further confirm what the chime-like stream of sextuplets already suggested: that each bell sound that appears in this piece need not be limited to a single pitch or single rhythmic attack. In many cases, the bells are instead represented by musical figures. Importantly, this allows us to conceive of the G\# octaves and the "echoes" that invariably follow at one octave above them as a single sound entity, which I call Bell Sound \#1 (BS1). The chime-like stream of sextuplets can then be thought of as Bell Sound \#2 (BS2) and the tolling perfect fourths can be thought of as Bell Sound \#3 (BS3). ${ }^{(10)}$

[13] I propose that the first section of "La vallée des cloches" (mm. 1-11) ultimately features five bell sounds: the three bell sounds mentioned in the previous paragraph are eventually followed in m. 6 by a single $G^{\text {t }}$ in a much lower register, and then by what Stephen Zank $(2009,168)$ calls an "insurgent" bell in the middle register, with its three repeated E\#s and accented mezzo-forte sound plainly contrasting the bell sounds that came before it (see Example 2). ${ }^{(11)}$ Each of the five bell sounds in this opening section is distinguished from the others in a variety of ways - by register, pitch pattern, rhythmic pattern, articulation, and, in some cases, dynamics. Furthermore, the bell sounds are repeated with little or no sense of growth or development, underscoring each individual bell sound's identity as a distinct entity by imbuing it with a sense of detachment or abstraction from its surroundings (see Mawer 2000,48).

[14] Although Ravel uses repetitions of bell sounds as a crucial way of distinguishing these entities from their surroundings, it is important to note that his repetitions are not always exact. Example 3 compares Ravel's score from mm. 1-4 to a hypothetical version in which the rhythmic pattern of BS1 from mm. 1-2 exactly repeats in mm. 3-4. From this example, we can deduce two reasons why Ravel did not choose to exactly repeat BS1's rhythmic pattern from $\mathrm{mm}$. 1-2. The first reason is practical: in the hypothetical version, it would become technically unfeasible for the pianist to clearly articulate both the sustained sound of BS1 and the rapid motion of BS2 in one hand. Secondly, in the hypothetical version, BS1 would overlap with the initial entry of BS3 in m. 4. By postponing the repetition of BS1 by one beat in $\mathrm{m}$. 4, as Ravel does, each bell sound can be more clearly individuated. Importantly, therefore, Ravel's use of repetition is strict enough to establish the different strands as individual bell sounds, yet is flexible enough to ensure that the aural distinction of each bell sound is not compromised.

[15] In all, I contend that there are twelve distinct bell sounds that appear in the piece, as summarized in Example 4. ${ }^{(12)}$ Although a few of the bell sounds share common features, what is strikingly apparent from Example 4 is how readily distinguishable the twelve bell sounds are from one another in terms of their pitch patterns, rhythmic patterns, register, texture, and in some cases, articulation; it is clear that Ravel went to some trouble to ensure that each of these individual bell sounds would be both visually and audibly identifiable. Eleven of the twelve bell sounds are distinguished as individual sound entities through the use of repetition; the only exception is BS8, an expansively melodic carillon appearing in the middle section of the piece, the character of which Ravel differentiates from the other surrounding bell sounds through the score indication largement chanté (sung broadly).

[16] "La vallée des cloches" divides into five sections (the boundaries of which are often delineated by long pauses), clearly projecting an overall arch form (A-B-C-B'- $\left.\mathrm{A}^{\prime}\right)$. This formal structure is mainly conveyed through the introduction of new bell sounds and the eventual return of bell sounds heard earlier in the piece. Although section boundaries are generally quite clear, Ravel bridges these divisions by temporarily maintaining at least one bell sound from the previous section every time a new section begins (see Example 5 for an illustration). Importantly, these connections between sections suggest the idea of moving - albeit at a rather deliberate pace-to different locations within the valley: a notion in keeping with Corbin's argument that bell sounds 
"conjur[e] up a space that is by its nature slow, prone to conserve what lies within it, and redolent of a world in which walking was the chief mode of locomotion" $(1998,96)$. As illustrated in

Example 5, the introduction in $\mathrm{m} .12$ of two new bell sounds (BS6 and BS7) coincides with the cessation of BS1, BS2, BS4, and BS5 to mark a clear section change, yet the persistent sound of BS3 across both sections evokes a sense of gradually moving from one area of the valley to another at a slow enough rate that one of the bell sounds from the preceding section can still be heard upon entering the new section. The path taken in progressing from the A section to the B section can therefore be traced through BS3, implying that BS3 acts as a sort of conduit through which the music moves from one location to the next.

\section{Constructing a map of the valley}

[17] The preliminary considerations highlighted in the preceding section point to a number of objectives that help to direct the process of constructing a map of "La vallée des cloches" in appropriate ways:

- Objective 1 (Path): the map should not only represent a set of spatial coordinates but should also highlight a path by which the valley is traversed as the piece progresses

- Objective 2 (Contiguity): bell sounds that occur simultaneously in the piece should be contiguous on the map wherever possible

- Objective 3 (Connections): the map should emphasize connections between sections of the piece

- Objective 4 (Form): the map should be laid out in a way that underscores the piece's overall formal structure

The four objectives listed here are interrelated and do not necessarily reflect any hierarchical order of preference. In a certain sense, however, the first objective can be seen as underpinning the others by providing an aesthetic foundation for constructing a map of the valley, whereas the remaining three objectives are practical considerations for creating a map that meets the first objective. This section of the article details my process of grappling with and weighing these objectives in order to ultimately construct a map fulfilling all four of the objectives. The map's visual layout is intentionally simple, and I do not claim that my final map represents the only way to map the piece. (13) It does, however, represent one possible way of mapping the valley that meets all of the above criteria and in turn provides a useful means of conceptualizing the piece.

[18] My process for creating a map of "La vallée des cloches" is influenced by David Lewin's discussion of methodological considerations involved in constructing a spatial representation of a piece of music (2007, 45-53). Lewin's analytical apparatus (a transformational network analysis) and the style of the piece he studied (Karlheinz Stockhausen's Klavierstück III) are admittedly quite different from those presented in this article. Despite these differences, however, a number of the methodological concerns that Lewin highlights are pertinent to the present study. Lewin famously draws a distinction between "figural" (narrative temporal) and "formal" (abstract spatial) aspects of representing a piece of music in spatial terms. ${ }^{(14)}$ He emphasizes that the different benefits that can be derived from figural and formal layouts prompt the analyst to constantly reference the unique characteristics of the piece in question in order to strike an appropriate balance between the two perspectives when positing a space through which the piece metaphorically "moves." My aforementioned four objectives in turn reflect an attempt to balance figural and formal concerns, and likewise stress a sense of movement through the valley as the piece progresses. The various versions of the maps that I will present in this section also echo Lewin's assertion that the value of creating a spatial representation of a piece of music lies not necessarily in the end result but rather in the process of creating it.

[19] The twelve distinct bell sounds I have identified in Example 4 are numbered according to their order of entry within the piece, an arrangement that, while facilitating apprehension of how the piece progresses in chronological time, also raises an important question: Should the bell sounds therefore be positioned on the map in order of entry as well? Example 6 presents a first attempt to map the opening two sections of the piece in this way. Bell Sounds 1-7 are arranged in a circular pattern according to order of entry, which provides a rather convincing way to visualize how the A 
section of the piece unfolds by capturing both the successive introduction of bell sounds in $\mathrm{mm}$. 16 and the sense of then being surrounded by these bell sounds in mm. 6-11. Constructing the map in this way becomes more problematic as the piece moves into the B section, however. The simultaneously occurring bell sounds of $\mathrm{mm} .12-13$ as well as those of $\mathrm{mm}$. 16-19 are not positioned contiguously, meaning that this chronologically oriented circular map does not conform to Objective 2 (Contiguity). Objective 3 (Connections) is also not met because the map does not emphasize the aforementioned connection between Section A and Section B facilitated by the continuation of BS3. It is therefore necessary at this point to adjust our heretofore figural map to include more formal features as well.

[20] Example 7 represents a second attempt to map the opening two sections of the piece. Two noticeable changes are that the first five bell sounds are now arranged in a V-shaped pattern with BS1 and BS2 switching places. This slight reorientation still convincingly captures the way the music unfolds in mm. 1-11, thus preserving many of the attractive figural features of Example 6. An added benefit of this new layout, however, is that by positioning BS6 and BS7 above BS3, BS4, and BS5, the simultaneous soundings of BS3, BS6, and BS7 in mm. 12-15 as well as that of BS4, BS5, and BS7 in mm. 16-19 are now emphasized by arranging these bell sounds contiguously on the map. Furthermore, the layout of Example 7 now underscores the connection between the A and B sections of the piece by facilitating a sense of movement from one area of the map to another, with BS3 providing a link between the two areas.

[21] As we now "zoom out" to view the valley as a whole in Example 8, the new bell sounds found in Section C can be convincingly positioned to the "east" with BS5 similarly acting as a link between the $B$ and $C$ sections. This synoptic version of our map is attractive in a number of respects: simultaneous bell sounds are laid out contiguously; connections between sections are clear; and the piece's overall arch form can be readily visualized as the map's layout facilitates a sense of departure and return.

[22] An additional benefit of the map presented in Example 8 is that it helps draw attention to one of the most striking moments in the piece. In m. 50, following the return of BS1, BS2, and BS3 that marks the beginning of the $\mathrm{A}^{\prime}$ section, a robust bell sound not originally heard in the A section powerfully announces its presence (recall Ravel's comment that this is the sound of " $\mathrm{La}$ Savoyarde"). This moment may initially seem to mark the appearance of a new bell sound, but a look back to the list in Example 4 indicates that this bell sound has in fact been heard earlier in the piece. Starting in $\mathrm{m} .28$, in the middle of the $\mathrm{C}$ section, the left hand sounds a chord in the low register made up of a perfect fifth stacked on top of a perfect fourth, rolled from bottom to top. While this chord from m. 28 is not articulated with the same force as the "Savoyarde" chord from $\mathrm{m}$. 50, the close similarity between their interval pattern and register-coupled with the fact that these are the only rolled chords in the entire piece-indicates that they should be considered a single bell sound (thus labeled as BS12 in Example 4). Thinking of these rolled chords as different articulations of the same bell sound then helps point out a striking sense of temporal proportion and balance underlying the piece's formal structure, and furthermore suggests a way to convincingly trace a path by which the valley is traversed as the piece progresses.

[23] Let us first consider the issue of temporal proportionality by revisiting the piece's opening two sections. The eleven-measure A section features no tempo fluctuations, which provides an equal basis for comparison among temporal spans. The accented entrance of the A section's final bell sound-BS5-occurs at the temporal midpoint of the section, thus indicating a precise sense of proportionality and balance underlying the section's temporal structure. The B section then reveals a similarly balanced temporal design. The B section is 35 quarter-note beats long (with no tempo fluctuations, just like the A section), with a division into two parts that is articulated by another accented entrance of the "insurgent" BS5 which occurs exactly 17.5 quarter notes into the sectiononce again, at the section's temporal midpoint. While not all of the piece's sections can be divided so precisely, the exactly balanced temporal divisions of the A and B sections indicate that creating such a sense of balance played an important role in Ravel's compositional approach, a strategy that can be further observed in the piece's overall temporal structure. ${ }^{(15)}$ 
[24] Considering the rolled chords at m. 28 and m. 50 as representing a single bell sound then helps uncover a precise temporal division underlying the whole piece that is reminiscent of the divisions articulated in the A and B sections. Overall, "La vallée des cloches" has 240 quarter-note pulses, and because Ravel marks no changes of tempo within the piece, it becomes reasonable to track these pulses as a way to measure the piece's temporal dimensions. The entrance in m. 28 of BS12, which we have now identified as the final bell sound of the piece, comes on the 120th beat - at the piece's overall temporal midpoint. This precise, equal division in the piece's overall temporal structure therefore mirrors the temporal divisions observed in the A and B sections. This temporal division also reinforces the piece's arch-like formal structure, with the entrance of the final bell sound marking the precise moment that, formally speaking, the music starts to turn back and ultimately return to where it started.

[25] In spite of the numerous beneficial features of Example 8's layout and the striking temporal divisions that it helps point out, its depiction of the $\mathrm{A}^{\prime}$ section is rather peculiar because BS12 is not positioned contiguously with BS1, BS2, or BS3 (the bell sounds whose recurrence marks the beginning of the $\mathrm{A}^{\prime}$ section). In fact, just the opposite is true; BS12's location on this map is maximally distant from those bell sounds. When BS12 is so powerfully articulated in $\mathrm{m}$. 50, we are then faced with a literal and figurative disconnection in that BS12 is not positioned contiguously with the other bell sounds from the A' section. Following the metaphor of traveling through the valley that so fundamentally underlies Objective 1 , it would seem impossible to suddenly jump from one location on the map to a far-removed location.

[26] By reorienting the bell sounds from the C section, as illustrated in Example 9, BS12 can be positioned adjacent to the other bell sounds from the $\mathrm{A}^{\prime}$ section. This revised layout still highlights the piece's overall formal structure by continuing to emphasize the sense of departure and return inherent to its arch-like formal design, yet now also presents a much more convincing picture of the concluding A' section by positioning all of its bell sounds contiguously on the map. This map in turn suggests an intriguing way of conceiving a path by which the valley is traversed: BS12 in one sense represents the point of furthest removal along the journey but in another sense also functions as the point to which we return at the end. Laying out the map as in Example 9 therefore not only fulfills our four objectives but also presents a thought-provoking way of conceptualizing the piece.

[27] To summarize, let us revisit the four objectives in reverse order and examine how the final map from Example 9 meets these objectives. This map underscores the piece's arch-like formal structure by laying out the bell sounds so that tracing the progression from Section A to B to C to B' and back to $\mathrm{A}^{\prime}$ suggests an arch-like shape. Furthermore, the connections between sections are clearly illustrated in that BS3 links Section A with Section B; BS5 then acts as a link between Section B and Section C; the "return trip" to Section B' then goes through BS10; and BS3 (along with a brief instance of BS6) then acts as a final link between Section B' and Section $\mathrm{A}^{\prime}$. Apprehension of the piece's formal structure as well as all of the connections between sections is accomplished by positioning simultaneously occurring bell sounds contiguously on the map. Through all of the characteristics described above, the map also highlights a convincing and thought-provoking path by which the valley is traversed as the piece progresses.

\section{Performance considerations}

[28] Many aspects of "La vallée des cloches" highlighted during the process of mapping the piece are closely aligned with choices a pianist would be faced with in performing it, including decisions about articulation, pacing, rubato, dynamic shading, phrasing and formal shaping, et cetera. A worthwhile first step in addressing these performance considerations is to consider two sources that provide at least somewhat direct access to information from the composer: Henriette Faure's recollections of advice Ravel gave her during the time he coached her on the piece, and a piano roll recording of Ravel himself playing the piece.

[29] The feedback Faure received during her coaching sessions with Ravel offers valuable insights into some aspects of the piece he felt were most important to bring out in performance: 
Ravel was merciless about my playing, which he condemned as heavy and unvaried in timbre. At the opening, he tried to get me to play the carillon of double semiquavers in the right hand, and the more settled sound of the high octave bells that punctuate them in the left, on two very distinct levels. And the whole thing had to remain within a pianissimo which he could, in some mysterious way, achieve without it sounding feeble. (Faure 1978, 79-80)

From Faure's recollections, which concern the bell sounds identified in this article as BS2 and BS1, respectively, it is clear that Ravel placed a high priority on making the identities of the individual bell sounds aurally distinguishable in performance. Importantly, this corroborates what we were earlier able to deduce from Example 4: that Ravel took care to ensure that each of the individual bell sounds would be both visually and audibly identifiable by clearly distinguishing them from one another in a variety of ways.

[30] A set of "Duo-Art" piano roll recordings of five of Ravel's works, including "La vallée des cloches," were released in the 1920s and were marketed as performances by the composer himself. Ravel admitted in a letter to M. D. Calvocoressi, however, that he recruited a better pianist than himself for some of the pieces; Orenstein $(2003,219)$ has identified that pianist as Robert Casadesus. Although the performer on the roll recording of "La vallée des cloches" has not been conclusively identified, Ronald Woodley notes that "the balance of probability favors the composer" (2000, 222), an assertion easily verified by comparing the precision of Casadesus's 1952 recording of the piece with what Roy Howat $(2009,321)$ calls "moments of mild anarchy between the hands" on the roll recording, the recording sessions for which took place in 1922. To what cause or causes Ravel's imprecise performance on the roll recording may be attributed is difficult to determine. In any case, the roll recording points to a significant gap between the precision of Ravel's compositional approach and the conspicuous lack of precision in his performance of the piece (see Example 10, and especially note the imprecise counting in mm. 4 and 6). Though Ravel's roll recording is quite attractive in some respects, its frequent moments of imprecision indicate a need to seek out additional models for interpreting "La vallée des cloches" in performance.

[31] I will now consider the ways in which a few of the salient aspects of "La vallée des cloches" highlighted during the process of mapping the piece align with significant considerations for performance by examining and comparing recordings by several illustrious pianists: a 1952 recording by Robert Casadesus, a 1956 recording by Walter Gieseking, a 1964 recording by Arthur Rubinstein, and a 1989 recording by Louis Lortie. ${ }^{(16)}$ These recordings were selected because Casadesus and Rubinstein were both longtime friends and artistic colleagues of Ravel as well as champions of his music, while Gieseking and Lortie can each be described as one of the most noted interpreters of Ravel's music from their respective eras.

[32] The first-and perhaps most important-performance consideration, which was emphasized by Faure in her recollections of Ravel's coaching, is to make the individual bell sounds aurally distinguishable from each other. What is striking from comparing the four recordings is how differently the four pianists approach this aspect of the music. Because the opening section of the piece features five different bell sounds, it offers a useful point of comparison in this regard (see Examples 11a-d). ${ }^{(17)}$

[33] Pacing is one prominent way of differentiating the bell sounds in performance. Rubinstein takes Ravel's Très lent indication to the extreme, loosely hovering around a tempo of 36 quarternote beats per minute (bpm) while also employing a great deal of rubato. Gieseking's tempo is much faster by comparison - at around $60 \mathrm{bpm}$ - and is initially stricter, although he employs a noticeable ritardando in the section's final four bars. Casadesus, on the other hand, keeps the tempo remarkably steady, at around $54 \mathrm{bpm}$. Finally, Lortie is the pianist who most closely approximates the recommended tempo of $50 \mathrm{bpm}$ in the score, and-similar to Casadesusmaintains a quite steady tempo. Interestingly, by ordering the four performances from slowest to fastest tempo, we also arrive at a convincing order for how distinct the individual bell sounds are on each recording. Might this indicate that differentiating individual bell sounds becomes more difficult at faster tempos? 
[34] Tempo is not the only factor in distinguishing the individual bell sounds, however. Rubinstein employs subtle pedal changes on the fourth eighth-note beats of $\mathrm{m} .6$ and $\mathrm{m}$. 8 , a tactic that helps mark the entrances of BS4 and BS5 by clearing out some of the accumulated sound, thus sacrificing some resonance in favor of clarity of voicing. Lortie, on the other hand, primarily distinguishes individual bell sounds by giving each one its own distinct and remarkably constant dynamic level, all the while maintaining resonance though more constant depression of the pedal. All four of the pianists also distinguish individual bell sounds through changes in articulation; this is most evident in the accented attack of BS5. Finally, Rubinstein and Gieseking also take extra time before the onset of BS5, further marking its entrance through the use of rubato. The diversity of means by which the bell sounds may be differentiated_including tempo/pacing, pedaling, dynamic shading, articulation, and rubato-points to one reasonable explanation for the wide variety of interpretations of this piece among performers.

[35] A second consideration highlighted during the mapping process that is relevant for performance is the connections between sections Ravel creates by maintaining bell sounds across sectional boundaries. Lortie's recording (see Example 11d) demonstrates two ways in which such a connection between the piece's A and B sections can be emphasized in performance: by maintaining a constant articulation and dynamic level for BS3 across sectional boundaries, and by keeping tempo constant between the two sections. While Rubinstein keeps a constant articulation and dynamic level for BS3 (see Example 11c) and Casadesus keeps a remarkably consistent tempo between sections (see Example 11a), Lortie's recording most clearly points out the connection between the A and B sections by highlighting these two factors in tandem.

[36] The third and final performance consideration that I will address here (though there are certainly others that could be mentioned) involves conveying the piece's formal design, which - as observed during the mapping process - is informed by precisely balanced temporal divisions. If this aspect of the piece seems most difficult to convey in performance, an explanation may be found in a fundamental opposition underlying performance and analysis studies stressed by Edward T. Cone $(1968,96-97)$ and Janet Schmalfeldt $(1985,17-18)$ : that analysis tends toward the synoptic while performance typically favors the immediate. The challenge is therefore that recognition of the balanced temporal divisions in "La vallée des cloches" seems accessible only through synoptic formal analysis, raising the question of just how salient this facet of the music is for performance. In an interview with John Rink, Murray Perahia notes that he initially tries to hear a piece without any preconceptions, and that he considers it a mistake to go too much into details of form before being able to hear the piece in his mind (Rink 2001, 10). This should not imply that Perahia sees no use in formal analysis but instead implies that as a performer, he gradually gains awareness of how a piece fits together formally through a bottom-up sort of process. The flutist Elizabeth McNutt (2005, [2]) similarly posits that in learning a piece, a performer "begins essentially without a map," moving from the specific to the general toward a coherent interpretation. While the kind of map to which she refers is more metaphorical than those presented in this article, her perspective mirrors Perahia's by suggesting a bottom-up approach in which a synoptic view is only achieved following a lengthy and detailed process of grappling with a piece's more immediate elements.

[37] While conveying form thus poses a difficult challenge in performance due to a lack of immediacy, Jonathan Kramer $(1988,52-54)$ hypothesizes that in the absence of such traditional temporal markers as tonal motion, harmonic rhythm, or overt articulations of metric hierarchy, proportional temporal relationships can be perceived through a process he calls "cumulative listening." The fact that such traditional temporal markers are noticeably absent from much of "La vallée des cloches" offers further clarification as to why the piece has been susceptible to widely varying interpretations by performers and analysts alike. If the precise temporal divisions underlying the piece's form are in fact possible to project in performance, Casadesus's recording points to two ways in which such perceptions might be facilitated. Firstly, Casadesus maintains a remarkably constant tempo throughout the piece, thus providing an equivalent basis for comparison among temporal spans. ${ }^{(18)}$ Secondly, his phrasing and dynamic shaping seem to mark the arrival of BS12 at m. 28 (the moment indicated by the mapping process to be the piece's precise temporal midpoint) as the climax of the piece. 
[38] This section has summarized the ways in which some noteworthy aspects of "La vallée des cloches" highlighted during the process of mapping the piece align in suggestive ways with a number of significant considerations for interpreting the piece in performance. While Daphne Leong and David Korevaar (2005) have noted a tendency among performance and analysis studies to proceed in one of two divergent directions - to present analyses and describe their implications for performance, or to study performances and examine their implications for analysis - my approach reflects an attempt to examine how insights gained from both perspectives can mutually reinforce one another. The maps presented in this article are not intended to serve as a prescription for a "good performance," but through their close alignment with salient performance considerations instead reflect Cone's assertion that "every valid interpretation thus represents, not an approximation of some ideal, but a choice: which of the relationships implicit in this piece are to be emphasized, to be made explicit?" $(1968,34)$.

\section{Conclusions}

[39] In this article, I have made a case for the value of mapping Ravel's "La vallée des cloches" by exploring how the process of mapping the piece can provide insights from a variety of perspectives. On the analytical side, the mapping process has offered a number of insights into the ways in which the piece's various bell sounds are individuated from each other, including the role of repetition in their individuation. The mapping process has also drawn attention to ways the bell sounds interact with one another in the creation of intricate formal designs, which include some highly precise and balanced temporal frameworks.

[40] The mapping process has also highlighted important aspects of Ravel's aesthetics such as the presence of mechanistic qualities, spatial and metaphorical thinking, literary influences, nostalgic fascination with the past, and the overall prominence of bells in his music. These aesthetic features also suggest an enlightening historical and cultural perspective on the piece: Ravel's evocation of a mechanical landscape suffused with bell sounds calls attention to significant changes in France at the turn of the twentieth century marked by the declining prominence of bells in defining the French auditory landscape, the symbolism bells carried with them, and the role bells played in marking temporal rhythms for French society as well as for individuals within that society.

[41] Additionally, many aspects of "La vallée des cloches" emphasized throughout the mapping process have been shown to closely align with significant performance considerations such as distinguishing the piece's bell sounds from one another (and the various ways in which pianists might go about doing so), emphasizing connections between sections of the piece, and ways a performer might conceivably convey the piece's formal design by means of underscoring its precisely balanced temporal frameworks. Examining how aspects of the piece highlighted by the mapping process align with performance decisions suggests ways in which the mapping and performance processes can relate to one another and offers some reasonable explanations for why such a wide variety of interpretations can be observed in performers' recordings of the piece. Although "La vallée des cloches" may be considered a confounding piece in many respects, the process of mapping the piece has pointed to some informative, multifaceted new ways of conceiving it.

[42] Might an approach similar to the mapping process presented in this article also be applied to other pieces of music? On one hand, Ravel's use of repeating, non-developmental layers of bell sounds to evoke a musical landscape was so novel that it seems almost without precedent-one of the only earlier pieces that might be considered a sort of precursor in this respect is "Klokkeklang" (Bell Ringing) from the Lyric Pieces, op. 54 by Edvard Grieg (a composer whose music Ravel greatly admired). On the other hand, some similar approaches to evoking musical landscapes can be posited in later works by other composers - a list that could include pieces such as Charles Ives's Central Park in the Dark, the "Liturgie de cristal" from Olivier Messiaen's Quatuor pour la fin du temps, Toru Takemitsu's Rain Tree Sketch II, and John Luther Adams's Become Ocean, among others. Significantly, each of the works mentioned above presents thought-provoking challenges for analyzing the music as well as realizing it in performance, and those considerations closely relate in each case to intriguing aesthetic, historical, and cultural contexts. The multifaceted approach to 
mapping Ravel's "La vallée des cloches" presented in this article therefore suggests a potentially productive avenue for exploring these and other "landscape" works as well.

Kyle Fyr

Mahidol University

College of Music

25/25 Phutthamonthon Sai 4, Salaya

Phutthamonthon, Nakhon Pathom, 73170 Thailand

kyle.fyr@mahidol.ac.th

\section{Works Cited}

Abbate, Carolyn. 1999. “Outside Ravel's Tomb." Journal of the American Musicological Society 52 (3): 465-530. https://doi.org/10.2307/831791.

Bamberger, Jeanne. 1991. The Mind Behind the Musical Ear: How Children Develop Musical Intelligence. Harvard University Press.

Benjamin, Walter. 1968. Illuminations. Edited by Hannah Arendt. Translated by Harry Zohn. Harcourt Brace Jovanovich.

Cone, Edward T. 1968. Musical Form and Musical Performance. Norton.

Corbin, Alain. 1998. Village Bells: Sound and Meaning in the Nineteenth-Century French Countryside. Translated by Martin Thom. Columbia University Press.

Faure, Henriette. 1978. Mon maître Maurice Ravel. Les Éditions ATP.

Fillerup, Jessie. 2013a. "Eternity in Each Moment: Temporal Strategies in Ravel's 'Le Gibet'." Music Theory Online 19 (1). https://doi.org/10.30535/mto.19.1.2.

_. 2013b. "Ravel and Robert-Houdin, Magicians." 19th-Century Music 37 (2): 130-58. https://doi.org/10.1525/ncm.2013.37.2.130.

Gubisch, Nina. 1980. "Le journal inédit de Ricardo Viñes." Revue international de musique française 1 (2): 154-248.

Gut, Serge. 1990. “Le phénomène répétitif chez Maurice Ravel: De l'obsession à l'annihilation incantatoire." International Review of the Aesthetics and Sociology of Music 21 (1): 29-46. https://doi.org/10.2307/836895.

Howat, Roy. 2009. The Art of French Piano Music: Debussy, Ravel, Fauré, Chabrier. Yale University Press.

Huebner, Steven. 2011. “Ravel's Poetics: Literary Currents, Classical Takes." In Unmasking Ravel: New Perspectives on the Music, ed. Peter Kaminsky, 9-40. Rochester University Press.

Jankélévitch, Vladimir. 1959. Ravel. Translated by Margaret Crosland. John Calder.

Kaminsky, Peter. 2000. "Vocal Music and the Lures of Exoticism and Irony." In The Cambridge Companion to Ravel, ed. Deborah Mawer, 162-87. Cambridge University Press. https://doi.org/10.1017/CCOL9780521640268.010.

Kelly, Barbara. 2000. “History and Homage." In The Cambridge Companion to Ravel, ed. Deborah Mawer, 7-26. Cambridge University Press. https://doi.org/10.1017/CCOL9780521640268.003.

_. 2013. Music and Ultra-Modernism in France: A Fragile Consensus, 1913-1939. The Boydell Press.

Kern, Stephen. 2003. The Culture of Time and Space, 1880-1918. Harvard University Press. 
Kieffer, Alexandra. 2017. "Bells and the Problem of Realism in Ravel's Early Piano Music." The Journal of Musicology 34 (3): 432-72. https://doi.org/10.1525/jm.2017.34.3.432.

Kilpatrick, Emily. 2015. The Operas of Maurice Ravel. Cambridge University Press. https://doi.org/10.1017/CBO9781316339237.

Kramer, Jonathan. 1988. The Time of Music: New Meanings, New Temporalities, New Listening Strategies. Schirmer Books.

Lanford, Michael. 2011. “Ravel and 'The Raven': The Realisation of an Inherited Aesthetic in ‘Boléro.'” The Cambridge Quarterly 40 (3): 243-65. https://doi.org/10.1093/camqtly/bfr022.

Leong, Daphne, and David Korevaar. 2005. “The Performer's Voice: Performance and Analysis in Ravel's Concerto pour la main gauche." Music Theory Online 11 (3). http://www.mtosmt.org/issues/mto.05.11.3/mto.05.11.3.leong_korevaar.html.

2011. “Repetition as Musical Motion in Ravel's Piano Writing." In Unmasking Ravel: New Perspectives on the Music, ed. Peter Kaminsky, 111-42. Rochester University Press.

Lewin, David. 2007. Musical Form and Transformation: Four Analytic Essays. Oxford University Press. https://doi.org/10.1093/acprof:oso/9780195317121.001.0001.

Margulis, Elizabeth. 2013. On Repeat: How Music Plays the Mind. Oxford University Press. https://doi.org/10.1093/acprof:oso/9780199990825.001.0001.

Marnat, Marcel. 1986. Maurice Ravel. Fayard.

Mawer, Deborah. 2000. "Musical Objects and Machines." In The Cambridge Companion to Ravel, ed. Deborah Mawer, 47-67. Cambridge University Press. https://doi.org/10.1017/CCOL9780521640268.005.

McNutt, Elizabeth. 2005. “A Postscript on Process.” Music Theory Online 11 (1). http://www.mtosmt.org/issues/mto.05.11.1/mto.05.11.1.mcnutt.html.

Nectoux, Jean-Michel. 1991. Gabriel Fauré: A Musical Life. Translated by Roy Howat. Cambridge University Press.

Nichols, Roger. 2011. Ravel. Yale University Press.

Orenstein, Arbie. 1991. Ravel: Man and Musician. Dover.

2003. A Ravel Reader: Correspondence, Articles, Interviews. Dover.

Puri, Michael. 2007. “Dandy, Interrupted: Sublimation, Repression, and Self-Portraiture in Maurice Ravel's Daphnis et Chloé (1909-1912)." Journal of the American Musicological Society 60 (2): 317-72. https://doi.org/10.1525/jams.2007.60.2.317.

2011. Ravel the Decadent: Memory, Sublimation, and Desire. Oxford University Press.

Rink, John. 2001. “Chopin in Performance: Perahia's Musical Dialogue.” The Musical Times 142 (1877): 9-15. https://doi.org/10.2307/1004572.

Roland-Manuel, Alexis. 1914. Maurice Ravel et son oeuvre. Durand.

Rossing, Thomas. 2000. Science of Percussion Instruments. World Scientific Publishing. https://doi.org/10.1142/4294.

Schafer, Raymond Murray. 1994. The Soundscape: Our Sonic Environment and the Tuning of the World. Destiny Books.

Schmalfeldt, Janet. 1985. “On the Relation of Analysis to Performance: Beethoven's 'Bagatelles' Op. 126, Nos. 2 and 5." Journal of Music Theory 29 (1): 1-31. https://doi.org/10.2307/843369. 
Smith, Richard Langham. 2000. "Ravel's Operatic Spectacles: L'Heure and L'Enfant." In The Cambridge Companion to Ravel, ed. Deborah Mawer, 188-210. Cambridge University Press. https://doi.org/10.1017/CCOL9780521640268.011.

Woodley, Ronald. 2000. "Performing Ravel: Style and Practice in the Early Recordings." In The Cambridge Companion to Ravel, ed. Deborah Mawer, 213-39. Cambridge University Press. https://doi.org/10.1017/CCOL9780521640268.012.

Wright, Barbara. 2005. “Baudelaire's Poetic Journey in Les Fleurs du Mal." In The Cambridge Companion to Baudelaire, ed. Rosemary Lloyd, 31-50. Cambridge University Press. https://doi.org/10.1017/CCOL052183094X.003.

Zank, Stephen. 2009. Irony and Sound: The Music of Maurice Ravel. University of Rochester Press.

\section{Selected discography}

Casadesus, Robert. 1998. Complete Piano Music of Ravel. Sony Classical 63316. CD.

Gieseking, Walter. 2017. Ravel: The Complete Works for Solo Piano. Warner Classics 0190295775063. CD.

Lortie, Louis. 2003. Ravel's Complete Works for Solo Piano. Chandos Classics 10142. CD.

Ravel, Maurice. 2013. Maurice Ravel Plays his Finest Works. Bringins Music B001BSXYC4I. CD.

Rubinstein, Arthur. 2000. The Rubinstein Collection, Vol. 43: Music of France (Ravel, Poulenc, Fauré, Chabrier, Debussy). RCA Red Seal 63043. CD.

\section{Footnotes}

1. To illustrate just how divergent conceptions of "La vallée des cloches" can be in Ravel scholarship, consider in brief the perspectives of Deborah Mawer and Vladimir Jankélévitch. Mawer (2000, 48-50) asserts that the piece exemplifies a tightly controlled, mechanistic manipulation of musical objects that can be found in a number of Ravel's works; Jankélévitch $(1959,36-37,88)$, on the other hand, uses words such as "dreamy," "misty," and "vagueness" to argue that the piece epitomizes a sort of "Swiss romanticism." Selected recordings illustrating a few of the diverse interpretations of this piece among performers will be discussed in the final section of this article.

Return to text

2. A number of scholars, including Carolyn Abbate (1999), Deborah Mawer (2000), as well as Daphne Leong and David Korevaar (2011), have examined certain mechanistic qualities that can be found in Ravel's music. Some of Ravel's own essays, such as "Finding Tunes in Factories," provide evidence of this type of thinking as well (see Orenstein 2003, 398-400). Serge Gut examines the specific issue of repetition in Ravel's music in some detail, though his discussion of "La vallée des cloches" is limited to repetitions of single notes, which he acknowledges "occupies only a relatively modest place" in the piece $(1990,32)$.

Return to text

3. Among the many references in Ravel scholarship to the influence of Baudelaire, Orenstein 1991, Nichols 2011, and Huebner 2011 offer useful introductions to how Baudelaire's writings and literary currents in general influenced Ravel, while some of the most in-depth explorations of how Baudelaire's ideas informed aspects of Ravel's life, personality, and music can be found in the work of Michael Puri (2011 and 2007).

Return to text

4. Orenstein and Nichols both suggest that Ravel's conception of sound closely relates to the distinctive sonic properties of the Erard, his preferred piano. Erard pianos have typically been noted for a light touch that facilitates rapid repetitions of notes as well as a thin, dry tone color, although Ravel's own Erard was noted for its breadth of sound (see Orenstein 1991, 81, 126; 
Nichols 2011, 40, 75, 320).

Return to text

5. Incidentally, Claude Debussy then published "Cloches à travers les feuilles" (Bells through the Leaves) as the first piece in his Images, Book II (1907). While a discussion of mutual influences between Debussy and Ravel is beyond the scope of this article, it is interesting to note how often Ravel's pianistic innovations actually preceded Debussy's: something Ravel felt compelled to point out in spite of his respect for Debussy (see Orenstein 1991, 31-33; Nichols 2011, 40-41).

Return to text

6. For a detailed account of bell symbolism in Baudelaire's poetry, see Benjamin 1968. Orenstein remarks that "No discussion of Ravel's aesthetics would be complete without commenting upon the decisive importance of Edgar Allan Poe's essays" (1991, 128), and then provides a brief summary of how Poe's essay Philosophy of Composition influenced Ravel's thought; similarly useful summaries can be found in Kelly 2000 and Kaminsky 2000. See Fillerup 2013b for a detailed discussion of how specific aspects of Poe's aforementioned essay intersect with Ravel's aesthetics, and for an exploration of how Poe's aesthetic philosophies may be specifically traced in Ravel's Boléro, see Lanford 2011.

Return to text

7. The physical properties of the auditory landscape that Corbin invokes strongly resonate with $\mathrm{R}$. Murray Schafer's notion of a "soundscape." Schafer (1994, 53-56, 173-77) likewise describes the prominence of bells in the soundscape throughout Europe's history.

Return to text

8. The journals of Ravel's friend, the pianist Ricardo Viñes, specifically mention that Ravel owned a copy of Les fleurs du mal (Gubisch 1980, 192).

Return to text

9. Puri 2011 presents a deep and multifaceted exploration of nostalgia in Ravel's music. For a few of the many other scholarly discussions of this topic, see Kilpatrick 2015, Kelly 2013, Nichols 2011, and Smith 2000.

Return to text

10. R. Murray Schafer $(1994,274)$ proposes a semantic distinction between sound objects and sound events, yet similarly defines both entities as the smallest self-contained units of a soundscape. In this article, I use the term "bell sounds" to refer to the smallest musical entities within this piece's auditory landscape.

Return to text

11. Kieffer (2017, 456-58) proposes an interesting alternate reading, which suggests the possibility of perceiving some of the opening section's bell sounds as reflections or resonance effects of other bells. For an introduction to some sonic properties of bells that can inform such a reading, see Rossing 2000, 128-45.

Return to text

12. All of the foregoing analyses (and the maps that accompany them) will refer to each of these bell sounds by number, so the reader will likely find it useful to either print Example 4 or keep it open for reference.

Return to text

13. I have kept the map's visual layout deliberately simple in order to emphasize the mapping process in a straightforward way. Mapping the piece using more elaborate visual layouts is certainly possible, however.

Return to text

14. Lewin openly acknowledges that his figural/formal distinction is based on the work of Jeanne Bamberger. For a concise explanation of this distinction, see Bamberger 1991, 24-26.

Return to text 
15. The presence of precisely balanced temporal divisions in this piece strongly corresponds with Ravel's well-documented sense of craftsmanship in his compositions (see Orenstein 1991, 118). Roy Howat $(2009,49-50)$ posits a temporal division in Ravel's Piano Concerto in G that is of similar precision and balance to those discussed in the present article. Recent scholarship also suggests ways in which time in general plays a prominent role in Ravel's compositions. For a detailed exploration of temporal processes in another of Ravel's "bell" pieces- "Le gibet" from Gaspard de la nuit-see Fillerup 2013a.

Return to text

16. The dates listed here refer to the years in which the recordings were originally issued. Return to text

17. Examples 11a-d illustrate not only each pianist's rendition of the piece's A section, but also the transition into the B section (the reason for which will be clarified shortly).

Return to text

18. Recall that the first entrance of BS5 occurred at the temporal midpoint of the A section. Interested readers may explore the extent to which they can perceive this section's precisely balanced temporal divisions "in real time" by revisiting Casadesus's recording in Example 11a. Return to text

\section{Copyright Statement}

Copyright (C) 2020 by the Society for Music Theory. All rights reserved.

[1] Copyrights for individual items published in Music Theory Online (MTO) are held by their authors. Items appearing in MTO may be saved and stored in electronic or paper form, and may be shared among individuals for purposes of scholarly research or discussion, but may not be republished in any form, electronic or print, without prior, written permission from the author(s), and advance notification of the editors of MTO.

[2] Any redistributed form of items published in MTO must include the following information in a form appropriate to the medium in which the items are to appear:

This item appeared in Music Theory Online in [VOLUME \#, ISSUE \#] on [DAY/MONTH/YEAR]. It was

authored by [FULL NAME, EMAIL ADDRESS], with whose written permission it is reprinted here.

[3] Libraries may archive issues of MTO in electronic or paper form for public access so long as each issue is stored in its entirety, and no access fee is charged. Exceptions to these requirements must be approved in writing by the editors of $M T O$, who will act in accordance with the decisions of the Society for Music Theory.

This document and all portions thereof are protected by U.S. and international copyright laws. Material contained herein may be copied and/or distributed for research purposes only.

Prepared by Lauren Irschick, Editorial Assistant

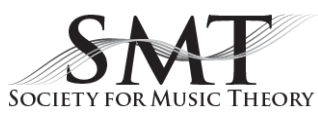

